\title{
EU FAÇO ARQUEOLOGIA ESCAVANDO A MINHA CASA
}

Carolina Kesser Barcellos Dias ${ }^{1}$

A disciplina Fundamentos da Prática Arqueológica, atualmente oferecida no segundo módulo do curso de especialização do curso lato sensu "Arqueologia, História e Sociedade" da Universidade de Santo Amaro - UNISA, foi estruturada com o objetivo de fornecer aos alunos os elementos necessários para compreender a natureza e a articulação das etapas do trabalho arqueológico, desde a definição das hipóteses iniciais do trabalho e a sua consolidação em um projeto de investigação em campo e laboratório, à elaboração de um relatório final de pesquisas e sua publicação, seja esta em forma de artigos e trabalhos científicos, seja em forma de ações educativas direcionadas à população.

Inicialmente ministrada pelo Prof. Dr. Álvaro Allegrette (de 2003 a 2007, com o título Metodologia do Trabalho Arqueológico), e posteriormente pela Prof. Dr. Cláudia Regina Plens (de 2007 a 2009, com a nomenclatura atual), a disciplina foi assumida por mim em 2010, mantendo seus objetivos de instrumentalizar os alunos para a prática arqueológica.

Embora desde sua criação o curso lato sensu preveja experiências em campo, não havia ainda se estruturado um projeto na universidade que providenciasse aos alunos etapas de campo e laboratório regularmente. Assim como para a maioria de nós arqueólogos ainda em formação, as oportunidades aos alunos da UNISA de escavar e analisar material arqueológico ocorreram por meio de convites de outros projetos em outras instituições.

Uma das principais preocupações desta disciplina, portanto, foi mostrar aos alunos que a prática arqueológica não se limita apenas à interferência direta em um sítio arqueológico, ou seja, não se limita exclusivamente ao momento da escavação. Com o apoio de uma bibliografia dedicada às técnicas de campo e laboratório, de teoria e método da arqueologia, e com exercícios constantes, os alunos tornam-se capazes de compreender aspectos práticos da Arqueologia sem, inicialmente, colocar a mão na terra.

Por isso, uma das atividades propostas durante os primeiros anos em que ministrei a disciplina foi a "escavação em casa". Foi solicitado aos alunos que escavassem seus armários, malas, estantes e, assim, desenvolvessem um programa arqueológico que deveria percorrer todas as etapas de um

1 Docente responsável pelo curso "Fundamentos da Prática Arqueológica" no curso Lato Sensu "Arqueologia, História e Sociedade" da Universidade de Santo Amaro desde 2010. 


\section{Revista de Arqueologia Pública}

projeto de pesquisa, desde o levantamento bibliográfico e a formulação de hipóteses, à escavação, o laboratório, e o relatório final.

Esta experiência mostrou-se bastante proveitosa. Os alunos construíam seus trabalhos acompanhando o programa das aulas expositivas (a saber, seis aulas em que são tratados os aspectos historiográficos da arqueologia, a formação do registro arqueológico, e as etapas de pesquisa desde a definição da problemática e o levantamento documental preliminar, a etapa de campo, de laboratório, ao relatório final e publicação), e ao longo do módulo produziram um trabalho final diretamente relacionado à prática arqueológica, embora não tivessem "cavado buracos" verdadeiramente em um sítio arqueológico.

Os alunos compreenderam de imediato a necessidade de responder a uma pergunta simples, mas fundamental: "afinal, para quê escavar?". Ao compreenderem que a arqueologia contribui com muito mais do que técnicas de escavação para recuperação de material, passaram a desenvolver uma pesquisa completa, que simulou e emulou etapas de escavação e do trabalho em laboratório, o que trouxe elementos para a compreensão do que se trata esse "fazer arqueologia", mesmo que dentro de suas próprias casas e com a sua própria e conhecida cultura material.

Esta atividade permitiu que os alunos se relacionassem teoricamente às técnicas de intervenção arqueológica, que tivessem uma primeira experiência prática de como pensar a etapa de escavação e como escolher a melhor maneira de abordar seu objeto de acordo com a realidade encontrada em seus "sítios". Mas o exercício não serviu apenas para o contato com os aspectos técnicos da escavação, houve um constante incentivo para que os alunos pensassem no porquê de desenvolver aquelas atividades, para quê abrir unidades de escavação naqueles locais determinados por eles, e qual a real importância do conhecimento prévio sobre a área e de seu potencial arqueológico. Os alunos puderam perceber a importância do planejamento e da pesquisa documental antes do início de qualquer intervenção no sítio, e durante a intervenção puderam pensar em novas estratégias de trabalho quando se deparavam com algum impedimento ou alguma dificuldade.

Aos alunos das turmas de 2011 e 2012 que obtiveram nota máxima em seus trabalhos foi proposto um exercício: que transformassem esses trabalhos em artigos que fariam parte da bibliografia básica da disciplina, e comporiam um material didático interno do curso de especialização². Esta proposta tomou outras proporções e os artigos compõem agora esta obra.

Cada um dos artigos representa um exercício de praticar a arqueologia e desenvolver o pensamento arqueológico com as ferramentas disponíveis. Além disso, reflete a capacidade de cada pesquisador em demonstrar como até mesmo os locais e os objetos com os quais nos relacionamos

${ }^{2}$ Os trabalhos, na íntegra, foram incorporados ao acervo da biblioteca da UNISA, e encontram-se à disposição para consulta.

\begin{tabular}{|l|l|l|l|l|l|l|}
\hline (C) Rev. Arqueologia Pública & Campinas, SP & v. 10 & n. 1 & p. 10-14 & MAR. 2016 & ISSN 2237-8294 \\
\hline
\end{tabular}




\section{Revista de Arqueologia Pública}

cotidianamente podem nos trazer informações tão interessantes e pertinentes quando aplicamos a eles o método, a prática e o olhar arqueológico.

No artigo Sítio Arqueológico Octalles Marcondes Ferreira, Cássia Aparecida Guimarães nos apresenta algumas possibilidades oferecidas pela prática arqueológica. Além de ser a única pesquisadora a empreender, de fato, uma experiência prática de escavação, a autora reflete sobre as possibilidades didáticas da Arqueologia. Nessa pesquisa, ela compõe uma equipe de "arqueólogos" formada por seus alunos do $6^{\circ}$ ano, os introduz aos métodos de intervenção no solo, à análise do material escavado em laboratório, convidando-os a refletir sobre o porquê de se desenvolver toda essa atividade para alcançar um objetivo: compreender o que é aquele espaço delimitado na escola, e porque ele se encontra daquela maneira atualmente. Este artigo aponta para o uso didático e público da arqueologia, estabelecendo um diálogo entre os resultados de uma pesquisa científica e o público.

O Projeto Nárnia, de Cinthya K. Ramos é desenvolvido em um ambiente íntimo e pessoal: seu quarto. Na pesquisa, a autora procura refletir sobre as mudanças operadas no espaço físico de maneira a adaptá-lo e adequá-lo às necessidades humanas em determinados períodos. Considerando o quarto como sua paisagem de pesquisa, a autora "escava" um sítio em particular, o guarda-roupas (Nárnia), em busca de respostas sobre o uso presumido de um ambiente ou objeto, e o que se encontra, de fato, lá. É preciso dizer que o nome atribuído ao sítio demonstra de forma criativa e lúdica a faceta romântica e mágica da Arqueologia que até mesmo o mais mal humorado arqueólogo não pode negar: como nossa disciplina nos permite encontrar caminhos para compreendermos aspectos humanos em outros tempos e espaços.

Gladys Mary Santos Sales em $O$ desenho infantil na construção da significação em Arqueologia Histórica: Análise de um caso oferece uma reflexão bastante densa sobre como o material arqueológico pode ser abordado. Desenvolvendo seu programa de pesquisas desde os levantamentos documentais, à intervenção do sítio e às análises de laboratório, a autora propõe ainda uma análise do material coletado que demonstra como determinadas abordagens interpretativas - aqui, a iconografia e a epigrafia -, e o apoio de outras áreas do conhecimento (no caso, a psicologia e a psicopedagogia) enriquecem o trabalho arqueológico ao fornecerem diferentes olhares e perspectivas.

Layla Chaves Lucena procurou compreender aspectos do cotidiano de um pequeno grupo doméstico por meio da observação da organização de um armário na cozinha de sua residência. Durante a Escavação em Casa, a autora desenvolveu a pesquisa cumprindo um programa arqueológico que a permitiu tecer reflexões acerca da estrutura socioeconômica e da organização do "sítio", a partir da análise e classificação dos aparelhos de jantar encontrados nele.

Assim como Layla Lucena, Marcos Rogério da Silva Moreira e Mauricio Resende abordaram questões socioeconômicas em seus respectivos trabalhos. Em Projeto Experimental do Trabalho

\begin{tabular}{|l|l|l|l|l|l|l|}
\hline (C) Rev. Arqueologia Pública & Campinas, SP & v. 10 & n. 1 & p. 10-14 & MAR. 2016 & ISSN 2237-8294 \\
\hline
\end{tabular}




\section{Revista de Arqueologia Pública}

Arqueológico: Arqueologia do Lixo, Marcos Rogério Silva Moreira nos apresenta um controlado estudo da área de serviço de seu apartamento a fim de compreender padrões de descarte e de consumo da população habitante daquela localidade. $O$ autor empreendeu em sua pesquisa prospecções e coletas de superfície, explicando o porquê da opção em não recorrer à escavação do sítio. Do ponto de vista didático, este artigo exemplifica e complementa os demais trabalhos, pois trata particularmente de uma técnica de campo que não havia sido particularmente discutida nos demais artigos até então.

Mauricio Resende vai para Debaixo da cama procurar respostas para os padrões de organização e descarte ocorridos em seu apartamento, mais particularmente no quarto de dormir. $O$ autor demonstra de maneira didática e cientificamente controlada todos os passos de seu programa arqueológico, desde as prospecções no quarto à "escavação" de sua cama, chegando a conclusões bastante interessantes sobre a ocupação daquele "sítio" em particular. Suas reflexões sobre a mudança de hábitos de consumo ao longo do tempo são extremamente ricas e pertinentes.

No Projeto Arqueológico Fundo Do Baú, Wagner Magalhães procura contar uma história de tradições e hábitos a partir de objetos encontrados em um baú. Apoiado em um conjunto de informações ricamente apresentadas em tabelas, gráficos e desenhos, o autor nos mostra como foi possível refletir sobre as contradições existentes no sistema de crenças de um dado agrupamento humano a partir da análise da cultura material, demonstrando, assim como no artigo de Gladys Sales, como diferentes abordagens e outras áreas do conhecimento compõem e enriquecem o trabalho arqueológico.

Todos esses artigos refletem os esforços de um grupo de pesquisadores em diferentes fases de formação em participar da construção do conhecimento arqueológico. Este dossiê é, portanto, uma obra coletiva, e seus objetivos superam aquele original - 0 de se produzir algo suficiente para a avaliação em uma disciplina - e também aqueles mais ambiciosos que procuram resolver todos os problemas científicos de uma área do conhecimento. Os artigos aqui reunidos revelam o comprometimento com um projeto didático, e, mais que tudo, demonstram um elevado grau de generosidade por parte de seus autores.

Generosidade porque cada um se empenhou em dobro para produzir o que será lido na sequência; primeiro, ao escreverem os trabalhos finais da disciplina Fundamentos da Prática Arqueológica e, depois, ao recuperarem, repensarem e reescreverem seus trabalhos para transformálos em artigos que, em conjunto, pudessem ser apreciados por todos os tipos de leitores fossem eles leigos ou de uma comunidade científica específica.

Os autores abriram as portas de seus quartos, lavanderias, cozinhas, salas, de seus locais de lazer e de trabalho para demonstrar como é possível observar padrões de organização - ou desorganização -, de uso e descarte, e de tudo o mais que seja cientificamente observável pela ótica arqueológica. Da maneira mais rigorosa possível, "escavaram" suas intimidades em um esforço

\begin{tabular}{|l|l|l|l|l|l|l|}
\hline (C) Rev. Arqueologia Pública & Campinas, SP & v. 10 & n. 1 & p. 10-14 & MAR. 2016 & ISSN 2237-8294 \\
\hline
\end{tabular}




\section{Revista de Arqueologia Pública}

coletivo de divulgá-las e discuti-las. Agradeço a cada um pelo comprometimento, seriedade e também a alegria e disposição com que abraçaram o projeto e produziram seus textos. E pela paciência, já que o processo de publicação desta obra tomou um considerável tempo, muito mais do que o prometido e esperado. Muito obrigada a todos.

Completando este grupo de generosos colaboradores, três pessoas fundamentais que atuaram em diferentes fases do que se concretiza neste dossiê: o Prof. Dr. Vagner Carvalheiro Porto, o Prof. Dr. Álvaro H. Allegrette e a Prof. Dr. Claudia Regina Plens. Ao longo desses dez anos do curso de especialização em Arqueologia da UNISA, esses três professores participaram da formação de novos pesquisadores e arqueólogos, ministrando aulas e palestras, orientando pesquisas, e aprimorando um quadro cada vez mais consistente de disciplinas oferecidas no curso. E participaram também, de diversas e importantes maneiras, de minha trajetória pessoal na Arqueologia.

Álvaro Allegrette, o primeiro docente a ministrar a disciplina Fundamentos da Prática Arqueológica, e um dos primeiros arqueólogos especializados na área de clássica - também minha área de especialização - que conheci quando comecei meus estudos em arqueologia, retorna aqui à sua disciplina prefaciando esta publicação.

Como apresentado por Vagner Porto em seu texto Arqueologia UNISA: 10 anos de trajetória, foi pela iniciativa de um grupo de colegas arqueólogos que o curso de especialização foi criado na Universidade de Santo Amaro. E foi Vagner Porto, coordenador do curso na UNISA, quem primeiro abriu as portas para a minha experiência de docência em arqueologia, convidando-me para integrar o corpo docente da Especialização, primeiro como professora da disciplina Arqueologia Histórica Geral e do Brasil e, posteriormente, da disciplina Fundamentos da Prática Arqueológica, que adotei para a vida. Com muito entusiasmo, recebeu a proposta de publicação deste dossiê; comprometido com o projeto, participou de todas as fases de correção e organização. E paciente, garantiu que todo esse longo processo de publicação fosse possível.

A oportunidade de me envolver com a Especialização na UNISA veio graças à indicação feita por Claudia Plens, que deixaria a UNISA na época para continuar sua exitosa carreira como arqueóloga e docente na Universidade Federal de São Paulo. Claudia Plens finaliza a publicação com seu brilhante texto O Mistério dos Objetos, em que tece uma importante reflexão sobre a classificação, abordagem e etapa imprescindível para qualquer estudo desenvolvido pela arqueologia.

Agradeço carinhosa e sinceramente aos colegas que não só apoiaram o projeto desta publicação, como aceitaram prontamente participar de todo o processo de leitura, comentários, correções, estruturação e, ainda, produziram os textos de abertura e finalização do dossiê. Para mim, a representação perfeita de um ciclo importante de trabalho, parceria e amizade. 